\title{
A PINTURA MODERNISTA NO RIO GRANDE DO SUL: TRADIÇÃO E INOVAÇÃO ${ }^{1}$
}

Maria Lúcia Bastos Kern

O objetivo do presente estudo é analisar as especificidades da pintura modernista no RGS, considerando o processo de modernização hipertardio e a situação de dupla subordinação deste estado: em relação ao eixo São Paulo/Rio de Janeiro e em relação aos países hegemônicos.

Outra finalidade é buscar compreender o sistema de arte, enquanto constituído por instituiçðes de produção, legitimação e consumo do objeto artístico, através da análise do discurso da crítica de arte, das ideologias visuais das escolas, do museu, das associações e das galerias de arte.

Inicialmente, para caracterizar a situação de dupla subordinação do estado é necessário comparar-se, brevemente, o desenvolvimento da modernidade na Europa; no Brasil e no RGS.

Deve-se salientar que a modernidade é entendida como os efeitos das mudanças sociais sobre o comportamento coletivo. É uma prática de vida social que se opõe à tradição, que se processa em todos setores da sociedade, mas não de forma homogênea.

Fazendo uma breve retrospectiva a partir do século XVIII, com os pensadores iluministas, percebe-se que a modernidade apresenta um caráter ideológico, pelo fato destes defenderem ideias liberais, dentre as quais pode-se citar a valorização do indivíduo e da organização racional da sociedade.

Mais tarde, com a revolução francesa, com a formação do estado moderno, com a revolução industrial, com o progresso científico e tecnológico e o desenvolvimento do sistema capitalista (só para citar alguns fatos), a modernidade torna-se um modo de vida social, que atinge amplos setores da sociedade e que se opõe à tradição.

Nesta etapa de transformaçao da ordem social, a modernidade é concebida como sinônimo de progresso, tendência positiva e linear que gera constantes conquistas em direção ao futuro.

A partir deste momento, a modernidade assume um significado de eficácia e, ao mesmo tempo, revolucionário, na medida em que rompe constantemente com o passado. 
É com este teor que se desenvolve a ideologia das vanguardas, as quais se rebelam contra a tradiçáo clássica, se proclamam frente ao seu tempo e como profetas da verdade, como uma modalidade de competição entre elas e que é própria ao sistema capitalista e aos fortes nacionalismos dominantes na Europa do início deste século.

Entretanto, as vanguardas lançam mão de outro passado, que não foi valorizado pelas academias, que é o da arte primitiva africana, da arte pré-colombiana, etc. Ao se apropriarem destas formas do passado, as destituem de seus significados originais e as aliam à inovação.

As vanguardas se peculiarizam também pela instituição do efêmero, pela construção e destruição, sem deixar cristalizar os seus postulados, e com isto se afastam do público que não consegue acompanhar todas as rápidas e complexas mudanças. Estas são promovidas tendo em vista não só o progresso, mas são também fruto das pressões do mercado de arte que no final do século XIX se estruturou segundo os moldes do próprio sistema econômico, exigindo sempre o novo e o original.

Mas, enquanto a modernidade nos países hegemônicos se processa em múltiplos setores da sociedade, sendo gerada por transformações ideológicas, políticas, econômicas, etc., no Brasil essa se introduz em alguns setores apenas, quase como uma espécie de efeito das mudanças na prática de vida social destes países.

\footnotetext{
"Um dos problemas da modernização no Brasil é justamente desta se processar em alguns setores, de maior interesse dos países industrializados, ao lado de outros que têm sua estrutura arcaica mantida, antes de produzir a mudança básica, que é a industrializaçđo autônoma e a constituição de um mercado interno". 2
}

A modernidade torna-se logo um modo de vida social, que se difunde parcialmente pela sociedade, gerando, assim, contradiçōes maiores do que as que normalmente ocorrem nos pałses hegemônicos.

A urbanização no Brasil em moldes modernos dá-se antes da industrialização peopriamente dita. Essa inicia no século XIX, graças, em parte, à introdução de nova tecnologia para o desenvolvimento dos engenhos no nordeste e para o estímulo da produção de café em São Paulo. Além desses fatos, pode-se destacar a abolição da escravatura que oportuniza o crescimento do mercado consumidor, e os serviços públicos que possibilitam a modernização das cidades. ${ }^{3}$

Em São Paulo, a modernidade torna-se uma prática social, devido. também ao fortalecimento do setor industrial, durante a la Guerra Mundial.

Com a crise do principal produto de exportaçao brasileiro - o café e as dificuldades de importação de produtos industrializados europeus, 
A estrutura da sociedade rio-grandense não oferece condiçð̄es para o desenvolvimento do modernismo, nos anos 20 e 30, como ocorre em S๔o Paulo e no Rio de Janeiro.

O sistema de representação visual é acadêmico, preso a uma série de convenções de tradição humanista, que foi transplantada para o Brasil pela Missão Artística Francesa, 1816. Estas convençðes de origem clássica são difundidas para todo país pelas instituiçōes da capital - Escola e Salão Nacional de Belas Artes - que exercem uma posição hegemônica em Relação à produção artística dos outros estados brasileiros.

Como instituiçбes oficiais sđo almejadas pelos artistas do RGS, seja para a obtenção de um aperfeiçoamento técnico, seja para a exposição de seus trabalhos. Pois, muitas vezes, o artista passa a ser valorizado, no estado, pelo fato de suas obras serem aceitas ou premiadas no Salão Nacional de Belas Artes.

Nesta época, a crítica de arte e o Salao exercem o papel de legitimação e de cotação ao nível de troca do objeto artístico.

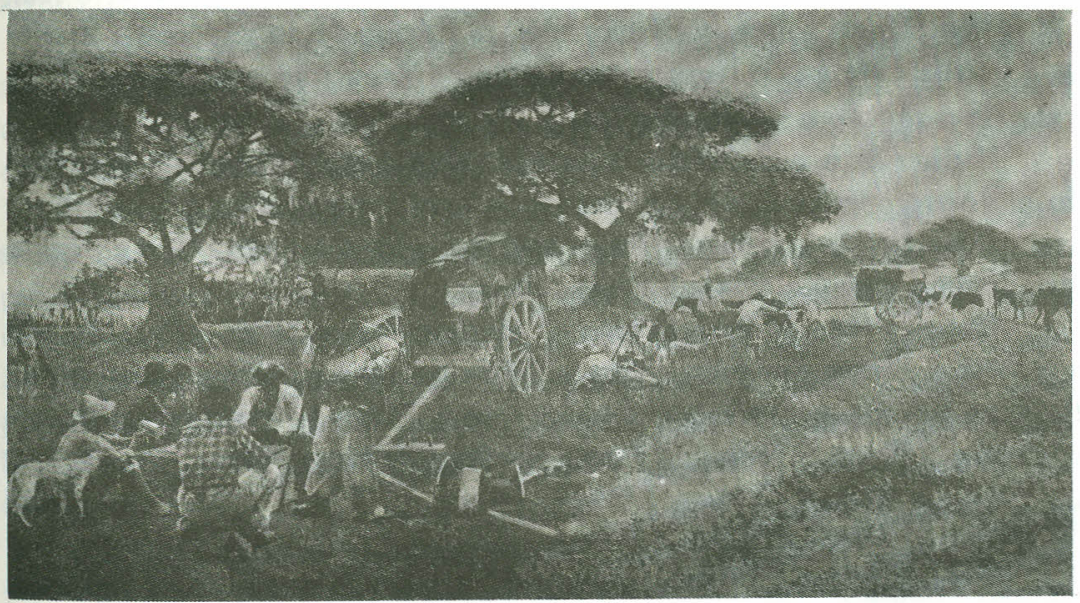

PEDRO WEINGÄRTNER - "Pousada", óleo, $37 \times 73 \mathrm{~cm}$ (Pinacoteca APLUB de Arte Rio Grandense Sid.)

Deve-se destacar que o ensino de artes no Estado é, neste momento, precário. Há somente uma Escola de Artes, a qual foi criada em Porto Alegre, em 1910. Esta escola tem muita dificuldade para selecionar professores, pois a maioria dos artistas plásticos que vivem no RGS não sđo titulados e não tiveram uma formação erudita e sistematizada. Aprenderam o ofí- 
cio no ateliê de outros artistas e o exercem nos fins de semana, como uma espécie de hobbie.

$\mathrm{O}$ número de manifestaçбes artísticas é tão pequeno e o campo de trabalho tão limitado que não oferece ao artista possibilidades de profissionalização, exceto como mestre. ${ }^{6}$

Além disso, os colecionadores e amadores gaúchos apreciam mais a arte do centro do paŕs e estrangeira, do que a arte local. ${ }^{7}$

Retornando à questão da arte acadêmica, deve-se salientar que o artista não se guia pela arte oficial do Rio de Janeiro, e conseqüentemente do pafs, como também é condicionado pela crítica de arte, constituída na sua mioria por escritores filhos de grandes proprietários rurais, que são muito conservadores. Para estes, a arte deveria ser a reprodução exata da natureza, de forma objetiva e detalhista, ñ̃o aceitando, assim, novas experiências e nem tentativas de renovaçao. Como é o caso, por exemplo, da tela "Marinha" de Augusto Luis de Freitas, exposta no Salão de Outono de 1925, a qual é qualificada de inferior, porque a pasta azul compacta, sem luz e sem transparência, pode representar tudo menos água. ${ }^{8}$

A crítica de arte exige o real, como se o pintor ao perceber o real, não o fizesse de forma condicionada. A fidelidade ao real, nada mais é para o artista do que o seguimento de regras figurativas, que são exteriores a ele, na medida que são instituídas.

Explica-se o comentário da crítica sobre a tela "Marinha", pelo fato do pintor romper com algumas das regras figurativas acadêmicas, ao utilizar cores mais vivas e constrastantes, pinceladas pastosas e visíveis, e ao quase abandonar o desenho pela valorização da cor.

Outro artista adota este tipo de pintura, realizada ao ar livre, na qual a luz e a cor provocam efeitos formais semelhantes à pintura impressionista. É Oscar Boeira que apreende a técnica com Eliseu Visconti, no curto período em que este lecionou na Escola Nacional de Belas Artes. 
Visconti assimila a técnica impressionista na França, difunde a alguns discípulos no Brasil, que, como ele, adotam, com uma certa defasagem, apenas os aspectos formais e técnicos, numa sociedade totalmente diversa, sem ter em vista as propostas e os objetivos originais dos pintores franceses.

Quando esta pintura surge no RGS, ela é impressionista somente na aparência. Ela não rompe com a tradição do desenho e da beleza, não provocando, deste modo, críticas muito acirradas como ocorreram com os artistas franceses.

Deve-se salientar que apesar da situação de dupla subordinação cultural e da defasagem da trajetória seguida pelas artes plásticas no estado, esta não é produzida como merá cópia, mas é fruto da seleção de símbolos que se adaptam melhor à ideologia visual dominante.

No período do Estado Novo (1937-1945) o sistema de arte no Rio Grande do Sul se dinamiza com a criaçao de novas instituiçбes. Em 1938, é fundada a Associação Rio-Grandense de Artistas Plásticos Francisco Lisboa por artistas que se encontravam à margem da Escola de Artes instituição que até 1938 mantinha-se como praticamente única instância de reprodução, legitimação e difusão do sistema visual oficial - e por alguns que trabalhavam na Editora Globo.

Neste mesmo ano, é concluída a reformulação da Escola de Artes, agora Instituto de Belas Artes que desde 1936 faz parte da Universidade de Porto Alegre. O novo currículo segue o modelo da Escola Nacional de Belas artes do Rio de Janeiro. ${ }^{9}$

Estas duas instituiçøes começam a promover anualmente Saloes, sendo que o. Instituto realiza o Salao Nacional nos moldes daquele da capital. Os salбes representam novos espaços para a apresentação de trabalhos dos artistas do estado, que até entao enfrentam dificuldades neste sentido. Representam ainda estímulo às novas pesquisas e à busca de atualização, pois os artistas passam por uma seleção para terem os seus trabalhos expostos de outros estados brasileiros, bem como a possibilidade de expor fora do RGS.

O maior dinamismo do sistema de artes oferece, paulatinamente, condições para a profissıonalização do artista plástico.

No início dos anos 40, ocorrem também as primeiras tentativas de modernização das artes plástıcas. Estas experiências são feitas por Carlos Scliar, Iberê Camargo, Carlos Petrucci, os quais não são compreendidos, sendo, assim, muito ridicularizados e limitados pela crítica de arte, por alguns professores e artistas influenciados por ideologias nacionalistas de extrema cireita. Eles acreditam, com Hitler, Plínio Salgado e outros líderes de movimentos nacionalistas que a introdução da arte moderna poderia desintegrar a sociedade e que esta é produzida por artistas "bolchevistas". 
Os discursos produzidos, nesta época, apresentam um teor estético moralizante e o medo de futuro desequilíbrio social.

"Ela (arte moderna) subverte a ordem e nivela por baixo, apresentando com suas extravagantes manifestações (...) um ambiente propício - pela ausência da ética, fonte pura da moral - um clima favorável à infiltração das idéias extremistas, perturbadoras do ritmo cristão em que há muito vive a Humanidade a sua luta pelo Ideal e pelo Belo".

Deve-se ter em vista que um grande número de artistas e professores são europeus ou de origem ${ }^{11}$ e que muitos são simpatizantes de ideologias nacionalistas de extrema direita.

Como as instituiçбes legitimadoras do objeto artístico e seus representantes ño admitem a mudança no sistema figurativo, a arte modernista não chega a se difundir muito no RGS, apesar da modernidade constituir uma prática de vida social.

Essa só é apoiada pelo diretor do DEIP - Departamento Estadual de Imprensa e Propaganda - Manoelito de Ornellas, escritor que, nos anos 20, atuou no grupo verde-amarelo.

Manoelito exerce no RGS papel semelhante ao praticado por Gustavo Capanema na capital do país, na medida que ele, como diretor do DEIP, apóia os artistas modernistas através de manifestos, de promoção de exposições e de apresentações em catálogos. Enquanto os interventores do estado e prefeitos concedem auxílios financeiros aos salōes promovidos pelo Instituto de Belas Artes, representando e oficializando assim a arte tradicional, no RGS.

O sistema pictórico dominante nestas manifestaçōes se aproxima em geral ao impressionismo, na medida que a pincelada é pastosa e visível, que as cores são luminosas e que a natureza é um dos temas preferidos. Entretanto, os artistas locais mantém a linha do desenho e o espaço em perspectiva, que é de origem humanista e que foi motivo de ruptura pelos impressionistas franceses. Como por exemplo as pinturas de Maristany, Ângelo Guido, Benito Castaffedo e outros.

O modernismo só começa a se difundir no RGS após o Estado Novo e a 2a Guerra Mundial, época em que a sociedade rio-grandense passa por um processo de modernização gerada pelo crescimento industrial e comercial, e o conseqüente fortalecimento econômico. A modernidade atinge, assim, setores mais amplos da sociedade, levando ao desenvolvimento não só da capital, mas também das cidades do interior do RGS, que também promovem manifestaçōes artísticas e fundam instituiçðes de ensino, como é o caso, por exemplo, de Pelotas. 
A partir de 1945, os artistas plásticos começam a fazer viagens de estudo para o exterior - Europa, Argentina e Uruguai; pelo Brasil, buscando a atualização e o aperfeiçoamento técnico.

Muitos artistas organizam grupos, como a Associação Araújo Porto Alegre, com o objetivo de realizar viagens de estudo pelo país e de se fortalecerem em oposição a velha geração de pintores tradicionais. Vão às cidades históricas mineiras e do nordeste, onde documentam a arte barroca e as manifestaçðes das culturas populares como uma espécie de resgate do passado e das produçoes simbólicas populares que foram desprezadas durante longo tempo pelos artistas acadêmicos.

Os artistas do RGS, quase trinta anos após, seguem trajetória semelhante àquela realizada pelos modernistas no centro do país, nos anos 20 . Por um lado, estão preocupados em se atualizar, e por outro, procuram pesquisar a arte do passado e as culturas populares contemporâneas, tendo em vista o uso de símbolos "nacionais".

Estes símbolos são apropriados, visando romper com o sistema visual tradicional, bem como a construção de uma identidade própria.

Além da Associação Araújo Porto Alegre promover viagens, a Associação Francisco Lisboa também realiza excursðes de artistas à região das antigas missões jesuíticas e a Rio Pardo, com o fim de estudar e registrar a arte produzida no passado.

Outros artistas, como Carlos Scliar, Danúbio Gonçalves e Vascos Prado, ao retornarem da Europa, embuídos pelo realismo socialista, fundam o Clube de Gravura de Porto Alegre e dirigem-se às estâncias da campanha com o objetivo de registrar hábitos e costumes regionais que estão desaparecendo no campo, devido à introdução da tecnologia. Procuram resgatar o regional, num momento em que o regionalismo é bastante estimulado através da criação de CTG e de poesias e contos literários. No entanto, estes artistas plásticos nao focalizam o gaúcho de modo ufanista, mas pelo contrário, o enfoque é crítico, na medida que apresenta o desaparecimento dos hábitos e costumes deste tipo social. Documentam o próprio desaparecimento do tradicional "gaúcho", isto é, a sua quase completa substituição pela máquina.

Eles desenvolvem a temática regional, conciliando-a com uma linguagem facilmente lida pelo leigo, com a finalidade de "popularizar a arte". É claro que não atingem este objetivo usando apenas a gravura e o sistema figurativo.

A manutenção deste sistema se deve também a oposição dos membros do Clube de Gravura em relação à penetração da arte abstrata internacional no centro do país, pois ño admitem a situação de subordinaçđo do Brasil aos países hegemônicos e as pressões do mercado de arte. 
Entretanto, estes artistas ao retornarem da Europa tentam implantar o realismo socialista, nao chegando a praticá-lo com o mesmo teor em que era comum nos países socialistas.

No final dos anos 40 e início dos anos 50, com a criação dos novos museus -- MASP (Museu de Arte de São Paulo), MAM (Museu de Arte Moderna) e da Bienal em São Paulo, e do MAM no Rio de Janeiro, a arte sofre nova internacionalização, com a vinda de exposiçбes dos movimentos de vanguarda da Europa e dos EUA. Nesta época, o mercado de arte no centro do país, estrutura-se com o aparecimento de várias galerias, passando juntamente com a crítica de arte a pressionar a produção artística, a qual passa a girar em torno do abstracionismo, construtivismo e concretismo.

Apesar de todas as manifestaçōes contrárias a internacionalização da arte feitas por estes artistas, alguns pintores do RGS praticam a abstraçđo. Como por exemplo, Cristina Balhão, Aldoir de Oliveira e, mais tarde, Iberê Camargo.

Ao lado destes trabalhos, encontram-se outros voltados mais às questões do nacional, do popular e da temática social, que elaboram pinturas cujas formas e propostas tinham sido adotadas pelos artistas modernistas do centro do país, dos anos 20 aos anos 40. Como por exemplo, Glênio Bianchetti, Paulo Flores, Plínio Bernhardt, etc...

Percebe-se que os artistas fazem experiências variadas dentro de propostas modernas, mas que não há um movimento organizado como o de São Paulo, na década de 20.

Como as novas pesquisas formais ocorrem com muita defasagem em relação aos grandes centros, essas peculiarizam-se por apresentar ao mesmo tempo quase todas as diferentes fases da arte moderna européia. Estão também mais orientadas à aparência e aos aspectos formais e técnicos, do que às idéias que estimularam o seu aparecimento. Visto que estas são adaptadas à estrutura social rio-grandense, sem romper completamente com a ideologia visual dominante e com o sistema visual tradicional.

Nos anos 50, o sistema de arte se dinamiza com o estabelecimento de novas instituições, como o MARGS - Museu de Arte do RGS, o Salão da Câmara Municipal de Porto Alegre, a Escola de Artes de Pelotas e algumas galerias de arte. Estas instituiçð̃es representam as novas instâncias de produção, legitimação e difusão do objeto artístico. ${ }^{12}$

Nesta época, a crítica de arte apresenta um discurso mais favorável ao modernismo, estimulando novas pesquisas e auxiliando, deste modo, d institucionalizaçđo das novas concepções e práticas artísticas. 


\section{NOTAS BIBLIOGRÁFICAS}

1 - Este artigo é fruto de comunicaçōes realizadas em simpósios, tendo como fonte norteadora a pesquisa produzida para a tese "La peinture moderniste au RGS" e estudos posteriores, como "O modernismo periférico: o caso da pintura no RS.", MARGS, 1985 (no prelo).

2 - KERN, Maria Lúcia B. "Modernidade e modernismo". ESTUDOS IBERO-AMERICANOS, 2 de dezembro de 1984, p.153.

3 - Id. Ibid., p.154.

4 - KERN, Maria Lúcia B. "Arte e ideologia: o modernismo nos anos 20" ESTUDOS IBERO-AMERICANOS 1-2, jul./dez., 1983, p.178.

5 - BOURDIEU, Pierre. "L'identité et la representation. Élements pour une reflexion crítique sur l'idée de Région". ACTES DE LA RECHERCHE EN SCIENCES SOCIALES 35, 1980, p.70.

6 - De 1920 a 1938, são realizados três saloes de arte em Porto Alegre 1925, Salao de Outono; 1929, Salao promovido pela Escola de Artes; e em 1935, Exposição do Centenário Farroupilha. O campo de trabalho limita-se a ilustrar capas de livros e da revista do Globo para a editora de mesmo nome; ilustrar poesias e contos na "Página Literária" do Diário de Notícias; fazer alguns retratos por encomenda; e lecionar.

7 - Na exposição do Centenário Farroupilha os colecionadores expø̃em os seus acervos, os quais se peculiarizam por um número muito pequeno de obras dos artistas do estado.

8 - JACK. "Salao de Outono", DIÁRIO DE NOTÍCIAS. Porto Alegre, 1 \% de Jan. 1925.

9 - Deve-se salientar que o currículo da Escola Nacional de Belas Artes do Rio de Janeiro já havia sido motivo de movimento de artistas dissidentes, em 1931, o Núcleo Bernadelli.

10 - KOETZ, E.; VIANA, J.F.; MONDIN Filho, G.; GOIDANICH. "Manifesto Anti-modernista", DIÁRIO DE NOTÍCIAS, 6 de Jan. 1942, p.7.

11 - ÂNGELO GUIDO, José Lutzemberger; TRIAS, Luis Maristany de; CORONA, Fernando; KOETZ, Edgar; GEIDANICH, Oswald, etc...

12 - Deve-se destacar que apesar da constituição de novas instâncias de difusão e de consumo da arte, ainda o mercado ño está estruturado nos moldes modernos, como direcionador e monopolizador da produção plástica. 